\title{
Resource-Based Method for Realizing Zero Emission of Sulfur Dioxide from Flue Gas
}

\author{
Xiang-Lian $\mathrm{HAN}^{1,2, \text { a }}$ and Xue-Xi CHEN ${ }^{1, \mathrm{~b}, ~ *}$ \\ ${ }^{1}$ School of chemical Engineering and Technology, Qingdao University of Science and Technology, \\ Qingdao, 266042, P.R. China \\ ${ }^{2}$ Department of chemical Engineering, Weifang Vocational College, Weifang, 261041, P.R. China \\ aangle.han@qq.com, bqdchenxuexi@163.com \\ ${ }^{*}$ Corresponding author
}

Keywords: Desulfurization; Zero emission; Resource utilization; Gypsum products

\begin{abstract}
A resource-based method for completely removal of $\mathrm{SO}_{2}$ from flue gas by utilizing recycling manganese hydroxide $\left(\mathrm{Mn}(\mathrm{OH})_{2}\right)$ as an absorbant was proposed, which utilized catalytic oxidation of the manganese in the air on the oxidation of sulfur dioxide to soluble sulfate while removing impurities by filtration to produce high value-added products. Eeffects of reaction temperature and $\mathrm{O}_{2}$ concentration on sulfite content and effects of $\mathrm{PH}$ value and $\mathrm{Mn}(\mathrm{OH})_{2}$ content on $\mathrm{SO}_{2}$ removal efficiency were investigated with a bubbling device to obtained the optimal experimental conditions. The method presented 100\% removal efficiency with regenerated absorbent, indicating a relatively thorough desulfurization, sulfur dioxide to achieve zero emissions by recycled $\mathrm{Mn}(\mathrm{OH})_{2}$ in this system. The sulfite content was very low, under $0.027 \%$, compared with manganese sulfate $10 \%$, which show the main component is sulfate ion, reaching to $99.7 \%$, further for the preparation of high quality gypsum products.
\end{abstract}

\section{Introduction}

As one of the major source of haze, sulfur dioxide $\left(\mathrm{SO}_{2}\right)$, received much attention from the government and the public, being emitted into the atmosphere harmfully affected the public health by irritating lungs and lowering resistance to respiratory infection (such as influenza)[1,2]. Up to date, many methods have been adopted for the removal of sulfur dioxide, including alkali solvents such as ammonium hydroxide[3,4], calcium hydroxide and magnesium hydroxide in aqueous slurries[5,6], and oxides and mixtures of oxides such as calcium oxide, magnesium oxide, iron oxide, and manganese oxides in dry solid state or in aqueous slurries[7-13], seawater ${ }^{[14]}$, and Limestone-gypsum[15,16], as well as organic compounds such as amines[17], etc. Among them, we know that wet scrubbing process has gained much more concern due to the $\mathrm{SO}_{2}$ is easily soluble in water and could be removed completely after scrubbing by absorbent, and manganese oxides $\left(\mathrm{MnO}_{\mathrm{x}}\right)$ have received special emphasis as a quite effective absorbent for sulfur dioxide recovery recently[11-13]. It was known that the $\mathrm{SO}_{2}$ in the emitted gases reacts with the manganese oxide to forms manganese sulfate, and then treated to regenerate back to the manganese oxide, which is quite effective as an absorbent, but it is uneconomical to regenerate since manganese sulfate is too stable to entirely decompose at temperature about $900^{\circ} \mathrm{C}$ [18], resulting in relatively high costs. Meanwhile, as the dominant technology in china, and domestic large power plant widely used, the 
lime/limestone process has been attracting the attention of the world due to its high efficiency and stability [19]. However, conventional methods of flue gas desulfurization (FGD) have various disadvantages, such as high capital cost, large occupation of land surface area, large consumption of fresh water, and formation of secondary pollutants [20]. In addition, with the difficulty of obtaining a grade of limestone high in calcium carbonate content, the sulfur dioxide from flue gases is absorbed by limestone under aqueous conditions to produce the low quality desulfurization gypsum requiring a large land surface area for disposal.

In this paper, the use of coupled chemical reaction to cycle desulfurization while reducing impurities to produce high quality gypsum products was proposed. According to the early studies, our research team adopted a method of removing sulfur dioxide from stack gases by using $\mathrm{Mn}(\mathrm{OH})$ 2 which is efficient in the removal of sulfur dioxide and readily handled and recycled to achieve resource utilization of desulfurization products. In this test, reaction temperature and $\mathrm{O}_{2}$ content on the absorption process were considered, as well as $\mathrm{pH}$ values and $\mathrm{Mn}(\mathrm{OH})_{2}$ concentrations on the influence of removal efficiency were tested to find the optimum experiment conditions, and the removal efficiency and sulfite content on different content of sulfur dioxide were studied under optimal conditions.

\section{Experimental}

\section{Experimental Materials}

All of the chemicals, such as calcium hydroxide ( $\geq 95.0 \%, \mathrm{AR})$, sodium hydroxide ( $\geq 99.0 \%, \mathrm{AR})$, manganese sulfate (99.0\%, AR), calcium nitrate (99.0\%, AR), sulfuric acid (98\%, AR), nitric acid (68\%, AR), iodine (99.8\%, AR), Sodium thiosulfate (99.0\%, AR) and deionized water, were used as received without further purification. The simulated flue gas was made up of $\mathrm{N}_{2}(99.999 \%), \mathrm{O}_{2}$ (99.999\%) and $\mathrm{SO}_{2}$ (99\%) (Qingdao, China).

\section{Experimental Apparatus and Procedure}

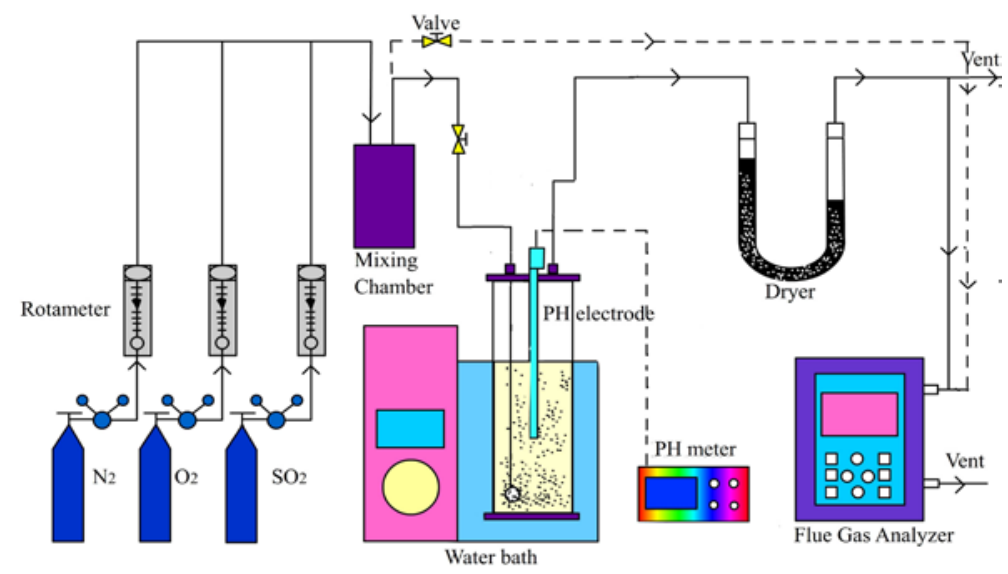

Fig. 1 Schematic diagram of the experimental apparatus for desulfurization

The experimental system of flue gas desulfurization includes a simulated flue gas system, a photochemical reactor and an analytical system. The experimental apparatus for desulfurization is shown in Fig. 1 that $\mathrm{N}_{2}$ and $\mathrm{SO}_{2}$ were supplied from the cylinders and mixed with oxygen completely in a mixing chamber before being fed to the reactor. The reactor was a bubbling device 
with a volume of $500 \mathrm{~mL}$ (60 $\mathrm{mm}$ in diameter and $160 \mathrm{~mm}$ in height). The gas flow rates were measured by gas rotameters which was $2 \mathrm{~L} / \mathrm{min}$. The reactor was immersed in a water bath for stable temperature. The $\mathrm{pH}$ value of the solution was adjusted with sodium hydroxide and was detected with a MP511 pH meter. $\mathrm{SO}_{2}$ and $\mathrm{O}_{2}$ concentrations at the inlet and outlet were measured continuously using British Kane KM950 flue gas analyzer. After the reactor, a desiccator was used to remove the water vapor in simulated flue gas to protect the flue gas analyzer. The manganese sulfate after desulfurization thereby produced can be used for regeneration of $\mathrm{Mn}(\mathrm{OH})_{2}$. The particle size was measured by Zetasizer Nano ZS90 nano-particle size analyzer.

The cycle absorption process only needs to add one material which is calcium hydroxide. The main reactions occurring in the experimental procedure may be stated as follows:

$$
\begin{aligned}
& \mathrm{Mn}(\mathrm{OH})_{2}+\mathrm{SO}_{2} \rightarrow \mathrm{MnSO}_{3}+\mathrm{H}_{2} \mathrm{O} \\
& 2 \mathrm{MnSO}_{3}+\mathrm{O}_{2} \rightarrow 2 \mathrm{MnSO}_{4} \\
& \qquad \mathrm{MnSO}_{4}+\mathrm{Ca}\left(\mathrm{NO}_{3}\right)_{2} \rightarrow \mathrm{CaSO}_{4} \downarrow+\mathrm{Mn}\left(\mathrm{NO}_{3}\right)_{2}
\end{aligned}
$$$$
\mathrm{Mn}\left(\mathrm{NO}_{3}\right)_{2}+\mathrm{Ca}(\mathrm{OH})_{2} \rightarrow \mathrm{Mn}(\mathrm{OH})_{2} \downarrow+\mathrm{Ca}\left(\mathrm{NO}_{3}\right)_{2}
$$

\section{Data Process}

The removal efficiency of $\mathrm{SO}_{2}$ with $\mathrm{Mn}(\mathrm{OH})_{2}$ was defined by the following formula:

$$
E_{f}(\%)=\frac{C_{\text {in }}-C_{\text {out }}}{C_{\text {in }}} \times 100 \%
$$

Where $E_{f}(\%)$ is the removal efficiency of $\mathrm{SO}_{2}, C_{\text {in }}\left(\mathrm{mg} / \mathrm{m}^{3}\right)$, and $C_{\text {out }}\left(\mathrm{mg} / \mathrm{m}^{3}\right)$ represent concentration of $\mathrm{SO}_{2}$ at inlet and outlet, respectively.

The method of iodimetry is used to analyze the content of sulfite. The calcium content in the regenerated manganese hydroxide was determined by EDTA titration.

\section{Results and Discussions}

\section{Sample Analysis}

The sample of $\mathrm{Mn}(\mathrm{OH})_{2}$ was regenerated under optimized conditions, and the contents of $\mathrm{Mn}(\mathrm{OH})$ 2 and $\mathrm{CaO}$ were analyzed. The main components of the absorbant are $\mathrm{Mn}(\mathrm{OH})_{2}$ which show greater than $94 \%$, compared with $\mathrm{CaO}$ less than $0.6 \%$. The particle size distribution is relatively concentrated, with an average particle size of about $350 \mathrm{~nm}$, easy to separate. The regenerated $\mathrm{Mn}$ $(\mathrm{OH})_{2}$ is easy to agglomerate and form larger particles, which leads to its good filtration performance. Easy to agglomerate to have larger specific surface area, the surface adsorption force is large, in order to ensure the regeneration of manganese hydroxide in flue gas desulfurization process can achieve the desired effect.

\section{Effects of Reaction Temperature and $\mathrm{O}_{2}$ Concentration on the Absorption Process}

The sulfite content in the absorption liquid was investigated when the accumulation of manganese sulfate reached $10 \%$ with the content of $\mathrm{Mn}(\mathrm{OH})_{2}$ was $1.0 \mathrm{wt} \%$ at different reaction temperature and $\mathrm{O}_{2}$ concentration which were shown in Fig. 2.

It can be seen from Fig. 2 that the sulfite content decreases from 0.096 to 0.0197 while the $\mathrm{SO}_{2}$ removal efficiency was $100 \%$ when the temperature increases from $25{ }^{\circ} \mathrm{C}$ to $65{ }^{\circ} \mathrm{C}$ under other 
conditions being equal, indicating the reaction temperature favors the conversion of sulfite to sulfate. It was known that the reaction temperature could influence the diffusion behavior, dissolution, and reaction characteristics of molecules or ions in liquid phase ${ }^{[20]}$. Therefore, the conversion rate of sulfite could be improved with increasing temperature. In additional, combined with the operating temperature for further denitration, the reaction temperature in this experiment to be determined was $55{ }^{\circ} \mathrm{C}$. As shown in Fig. 2, the sulfite content decreases as the $\mathrm{O}_{2}$ concentration increases from $4.0 \%$ to $6.8 \%$, and then the sulfite content varies little in the range from $6.8 \%$ to $9.5 \%$ with other conditions unchanged. We know that the reaction of the $\mathrm{Mn}(\mathrm{OH})_{2}$ and $\mathrm{SO}_{2}$ to manganese sulfate consumes oxygen, and for this reason, there should be a sufficient supply of oxygen to the absorbant slurry to support the conversion of sulfite to sulfate. Therefore, the results show that the absorption of $\mathrm{SO}_{2}$ could be improved with increasing $\mathrm{O}_{2}$ concentration and the $6.8 \%$ is sufficient in this slurry system.
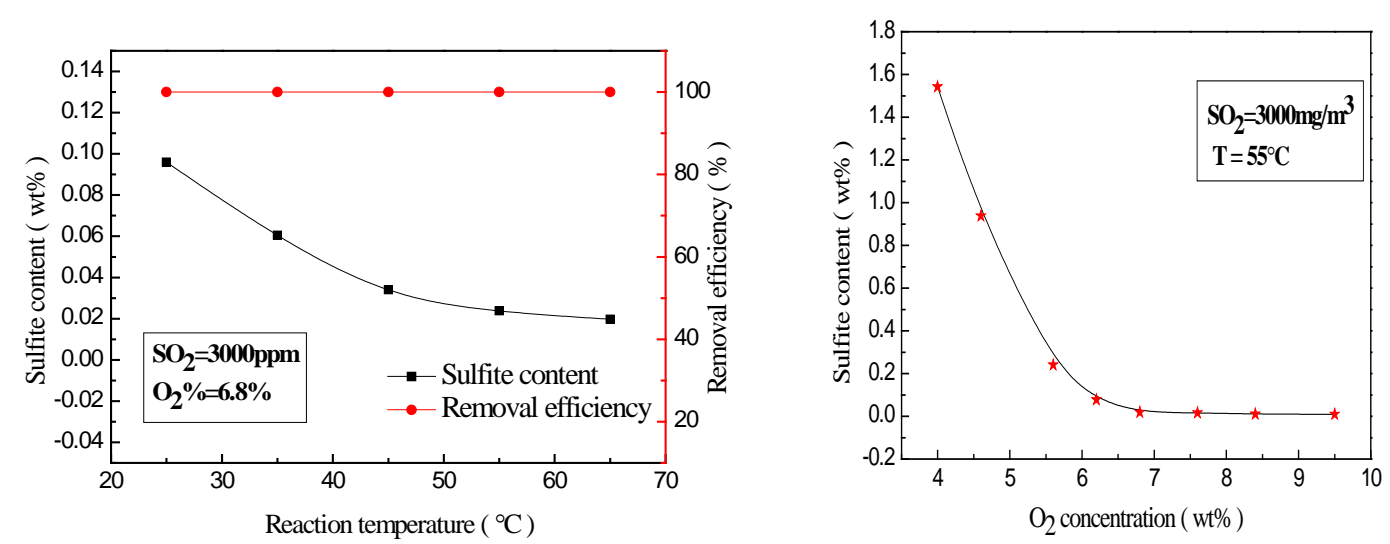

Fig. 2 Effects of reaction temperature and $\mathrm{O}_{2}$ concentration on the absorption process
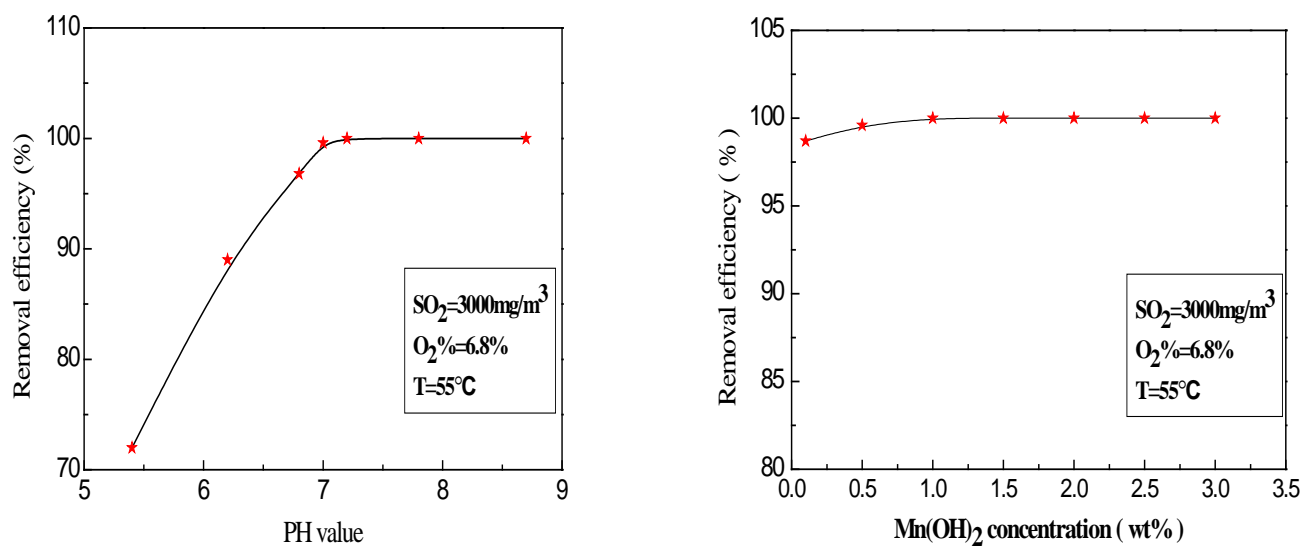

Fig. 3 Effects of $\mathrm{PH}$ value and $\mathrm{Mn}(\mathrm{OH})_{2}$ content on $\mathrm{SO}_{2}$ removal efficiency

\section{Effects of PH Value and $\mathrm{Mn}(\mathrm{OH})_{2}$ Content on $\mathrm{SO}_{2}$ Removal Efficiency}

Fig. 3 shows the $\mathrm{SO}_{2}$ removal efficiency with various slurry $\mathrm{pH}$ values and different $\mathrm{Mn}(\mathrm{OH})_{2}$ content at the temperature $55{ }^{\circ} \mathrm{C}, \mathrm{SO}_{2} 3000 \mathrm{mg} / \mathrm{m}^{3}$, and $\mathrm{O}_{2} 6.8 \%$. It is obvious that the removal efficiency rapidly increases as the slurry $\mathrm{pH}$ value increases from 5.4 to 6.8 , gets to the $100 \%$ at 7.2 and remains unchanged from 7.2 to 8.7. The effect of $\mathrm{Mn}(\mathrm{OH})_{2}$ concentration varies little as the slurry range from 0.1 to 5.0 percent by weight (wt \%). The results show that the content of $1.0 \mathrm{wt} \%$ is sufficient in this slurry system. Generally, higher values of $\mathrm{Mn}(\mathrm{OH})_{2}$ being used in the 
experiment, the higher amounts slurry will be employed, which should be a higher efficiency.

According above, the optimum experiment conditions were selected, and the experimental results of desulfurization in the suitable conditions are shown in Fig. 4. It could be observed that $\mathrm{SO}_{2}$ of different content from $1800 \mathrm{mg} / \mathrm{m}^{3}$ to $3000 \mathrm{mg} / \mathrm{m}^{3}$ were cleaned up by $\mathrm{Mn}(\mathrm{OH})_{2}$ with the removal efficiency of $100 \%$. It also can be seen that the sulfite content varies little from $1800 \mathrm{mg} / \mathrm{m}^{3}$ to 3000 $\mathrm{mg} / \mathrm{m}^{3}$, compared with manganese sulfate $10 \%$ which show the main component is sulfate ion, reaching to $99.7 \%$. We know that $\mathrm{SO}_{2}$ was a soluble gas, and could rapidly react with water to form weakly acid, it is theorized that the somewhat basic property of $\mathrm{Mn}(\mathrm{OH})_{2}$ is utilized in the process through the mechanism of a standard acid-base reaction to facilitate $\mathrm{SO}_{2}$ removal. The reaction between the $\mathrm{Mn}(\mathrm{OH})_{2}$ and the $\mathrm{SO}_{2}$ was very fast with the advantage being taken of the known catalytic effect of the manganese compounds on the oxidation of sulfur dioxide in an aqueous system. In addition, it should be a sufficient supply of oxygen to the conversion of the $\mathrm{Mn}(\mathrm{OH})_{2}$ and $\mathrm{SO}_{2}$ to soluble manganese sulfate, facilitating absorption.

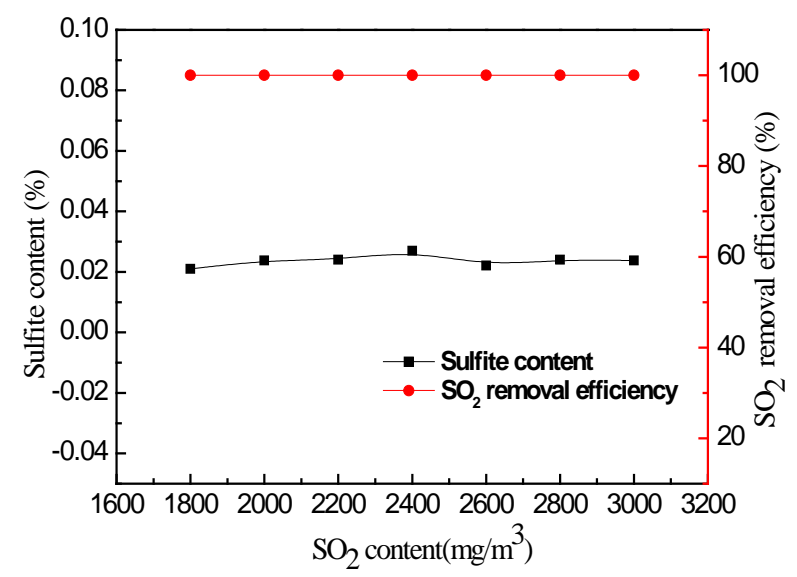

Fig. 4 Experimental results of simulated flue gas on $\mathrm{SO}_{2}$ removal $\left(\mathrm{T}=55^{\circ} \mathrm{C} ; \mathrm{O}_{2}=6.8 \%\right.$;

Gas flow rate $\left.=2 \mathrm{~L} / \mathrm{min} ; \mathrm{Mn}(\mathrm{OH})_{2}=1.0 \mathrm{wt} \%\right)$

\section{Conclusions}

A resource-based method for completely removal of $\mathrm{SO}_{2}$ from flue gas by using recycling manganese hydroxide ( $\mathrm{Mn}(\mathrm{OH})_{2}$ ) as an absorbant was proposed. The effects of reaction temperature and $\mathrm{O}_{2}$ concentration on absorption process and the effects of $\mathrm{PH}$ value and $\mathrm{Mn}(\mathrm{OH})_{2}$ content on $\mathrm{SO}_{2}$ removal efficiency were considered to achieve the optimal experimental conditions which were $\mathrm{T} 55^{\circ} \mathrm{C}, \mathrm{O}_{2} 6.8 \%, \mathrm{Mn}(\mathrm{OH})_{2} 1.0 \mathrm{wt} \%$, and $\mathrm{PH} \geq 7.2$. Under the optimal conditions with a bubbling device, $\mathrm{SO}_{2}$ of different content from $1800 \mathrm{mg} / \mathrm{m}^{3}$ to $3000 \mathrm{mg} / \mathrm{m}^{3}$ in the experiment could achieve $100 \%$ removal efficiency, indicating that desulfurization by the recycled manganese hydroxide was thorough. The sulfite content in the absorbing liquid was relatively low, under $0.027 \%$, compared with manganese sulfate $10 \%$, which show the main component is sulfate ion, reaching to $99.7 \%$, suitable for the preparation of high quality gypsum products and the regeneration of $\mathrm{Mn}(\mathrm{OH})_{2}$.

\section{Acknowledgements}

This work was financially supported by the Shandong Province key development Projects (2015GSF117010). 


\section{References}

[1] M. K. Mondal, V. R. Chelluboyana, New experimental results of combined $\mathrm{SO}_{2}$ and $\mathrm{NO}$ removal from simulated gas stream by $\mathrm{NaClO}$ as low-cost absorbent, J. Chem. Energy. 217(2013) 48-53.

[2] E. H. Duan, P. Zhang, K. Yang, W. Z. Liang, M. T. Yu, S. Wang, J. R. Niu, Effect of alkyl and halide moieties on the absorption and stratification of $\mathrm{SO}_{2}$ in tetrabutylammonium halide aqueous solutions, J. RSC Adv. 6(2016) 55401.

[3] X.Gao, H. L. Ding, Z. Du, L. Wu, M. X. Fang, Z. Y. Luo, K. F. Cen, Gas-liquid absorption reaction between $\left(\mathrm{NH}_{4}\right)_{2} \mathrm{SO}_{3}$ solution and $\mathrm{SO}_{2}$ for ammonia-based wet flue gas desulfurization, $\mathrm{J}$. Appl. Energy. 87 (2010) 2647.

[4] J. B.Gao, S. J. Wang, J.Wang, L. D. Gao, S. W. Tang, Y. Xia, Effect of $\mathrm{SO}_{2}$ on the amine-based $\mathrm{CO}_{2}$ capture solvent and improvement using ion exchange resins, J. Int. J. Greenh. Gas Control. 37 (2015) 38-45.

[5] C. F. Liu, S. M. Shih, R. B. Lin, Kinetics of the reaction of Ca $(\mathrm{OH})_{2}$ /fly ash sorbent with $\mathrm{SO}_{2}$ at low temperatures, J. Chem. Energy. Sci. 57(2002) 93.

[6] Z. G. Shen, M. J. Ni, S. P., Guo, X., Chen, M. Tong, J. Lu, Kinetics of Oxidation Inhibition of Sodium Sulphite in Wet Flue Gas Desulphurization Process, J. Asian. J. Chem. 25(2013) 6727

[7] S. M. Shih, J. C. Lai, C. H. Yang, Kinetics of the reaction of dense cao particles with $\mathrm{SO}_{2}, \mathrm{~J}$. Ind. Eng. Chem. Res. 50(2011) 12409.

[8] R. D. Valle-Zermeño, J. Formosa, J. A. Aparicio, M. Guembe, J. M. Chimenos, Transposition of wet flue gas desulfurization using MgO by-products: From laboratory discontinuous batch reactor to pilot scrubber, J. Fuel. ProcessTechnol. 138(2015) 30.

[9] J. Przepiórski, A. Czyżewski, J. Kapica, D. Moszyński, B. Grzmil, B. Tryba, S. Mozia, A. W. Morawski, Low temperature removal of $\mathrm{SO}_{2}$ traces from air by MgO-loaded porous carbons, J. Chem. Eng. 191(2012) 147.

[10]Y. Yang, S. T. Tong, Progress of study on iron oxide desulfurizer at ambient temperature, J. Gas Heat, (2002).

[11]Y. Liu, J.Sun, X. X.Hu, Shu, S. J, Ding, S. L, Yu, Z. L., Study on flue gas desulfurization with rhodochrosite and pyrolusite pulp, J. China’s Manganese Ind. 26(2008) 19.

[12]Y W. Qi, Y. J.Li, L. Kong, M. M.Ren, Q.,Han, Feasibility of flue-gas desulfurization by manganese oxides, J. Soc. Ch. 23(2013) 3089.

[13]Y. Osaka, T. Kito, N. Kobayashi, S. Kurahara, H. Y. Huang, H. R. Yuan, Z. H.,He, Removal of sulfur dioxide from diesel exhaust gases by using dry desulfurization $\mathrm{MnO}_{2}$ filter, J. Sep. Purif. Technol, 150(2015) 80.

[14]S. Darake, M. S. Hatamipour, A. Rahimi, P. Hamzeloui, $\mathrm{SO}_{2}$ removal by seawater in a spray tower: Experimental study and mathematical modeling, J. Chem. Eng. Res. Des. 109(2016) 180.

[15]D.Lei, Energy-efficient investigation of flue gas desulfurization by limestone-gypsum method. J. Technol. Development. Chem. Ind. 2011.

[16]C. Chen, S. Liu, G. Yang, Y. Liu, Investigation on mercury reemission from limestone-gypsum wet flue gas desulfurization slurry, J. Sci. World. 1(2014) 171. 
[17]Y. Q. Guo, Application of organic amine process in flue gas desulfurization of sintering machine, J. Ch. Environ. Protection Ind. 2013.

[18]R. Ben-Slimane, M. T. Hepworth, Desulfurization of hot coal-derived fuel gases with manganese-based regenerable sorbent. 2. Regeneration and multicycle tests, J. Energy Fuels. 8(1994) 1175.

[19]Z. Yan, L. Liu, Y. Zhang, J. Liang, J. Wang, Z. Zhang, X. Wang, Activated semi-coke in $\mathrm{SO}_{2}$ removal from flue gas: selection of activation methodology and desulfurization mechanism study, J. Energy Fuels. 27(2013) 3080.

[20]Y. Liu, T. M. Bisson, H. Yang, Z., Xu, Recent developments in novel sorbents for flue gas clean up, J. Fuel Process. Technol. 91(2010) 1175. 